\title{
Council Reports
}

\section{Psychiatric rehabilitation - revised}

This new policy document, approved by the Council of the Royal College of Psychiatrists, sets out the changes that there have been to this important sub-speciality of general psychiatry in the past eight years. Drawing on the principles of social and biological psychiatry together with those of applied psychology, modern psychiatric rehabilitation has demonstrably improved the lives of those people with enduring severe mental illness.

The document sets out the scope of rehabilitation which includes the target population, the tasks to which it addresses itself, and the skills that are necessary to provide the means to achieve good practice. It describes the varying locations, both within the hospital service and the community, where rehabilitiation services need to be applied. The integration of rehabilitation services with the community mental health teams is discussed with particular emphasis on developing local agreements to ensure smooth, progressive and seamless care delivery systems. A section on the training of psychiatric rehabilitation consultants of the future is included together with manpower considerations.

It is hoped that this document will prove useful to all those who have an interest in purchasing and providing services for persons with enduring severe mental illness and will also demonstrate to psychiatrists in training that rehabilitation offers a full and rewarding career.

Full report available from the College Book Sales Office, price $\$ 5.00$, CR 46.

\section{College policy statement on rape}

This statement replaces the memorandum on rape which was approved by Council in 1975. It reflects the considerable advances in knowledge about rape and its effects, as well as the intervening changes in the law which have affected the definition, processing and prosecution of rape claims.
Within the document the term 'rape' is used to encompass a wide range of sexual assault and adverse sexual experiences. While the majority of victims are female (reflected by the use of the pronoun 'she' in parts of the document), men are also sexually assaulted, a fact that has only recently been given legal recognition. Although stranger rape is a common stereotype, most women are raped by someone they know. Victims of acquaintance rape are less likely to achieve a successful conviction than women raped by strangers. It is more difficult to prove nonconsent when evidence is presented of consensual sexual relations having occurred in the past. The closer the relationship between victims and alleged perpetrator the more likely it is that she will be regarded as a willing participant, rather than a rape victim.

Specially vulnerable groups include victims of domestic violence, children, street workers, the learning disabled, and psychiatric in-patients. This document discusses the following areas:

- the legal position and criminal justice procedure;

- the effects of rape and any subsequent legal proceedings on victims;

- support and treatment;

- the role of the psychiatrist in supporting/ treating rape victims.

Also included is a brief review of characteristics of sex offenders, only a minority of whom are likely to require or respond to treatment. This last section has been added on the basis of our belief that in attempting to understand and offer help to the victims of sexual assault, it is helpful to be informed about the other half of the offence equation.

It is hoped that this statement will raise awareness of rape and its impact on psychological health, interpersonal and social functioning, in order to highlight the needs of rape victims and to enhance the capacity of psychiatrists to meet those needs.

Full report available from the College Book Sales Office, price $£ 7.50$, CR47. 